\title{
As Concepções de Geometrias não Euclidianas de um Grupo de Professores de Matemática da Educação Básica
}

\author{
Concepts of non-Euclidean Geometries of a Group of Math teachers From \\ Primary Schools
}

\author{
Karla Aparecida Lovis ${ }^{*}$ \\ Valdeni Soliani Franco ${ }^{* *}$
}

\begin{abstract}
Resumo
Este artigo apresenta uma pesquisa em que foram identificadas e analisadas as concepções sobre Geometrias não Euclidianas de um grupo de 27 professores de Matemática, da Educação Básica, que atuam em escolas públicas do Estado do Paraná. Para atingir o objetivo, procurou-se averiguar os conhecimentos, as opiniões, as preferências e as ideias que os participantes da pesquisa apresentam a respeito dessas Geometrias. A escolha desses participantes realizou-se por meio de um questionário, e a coleta dos dados adveio de uma entrevista semiestruturada. Constatou-se que seis professores não apresentam concepções sobre o assunto e, dentre estes, um professor não sabia da inclusão das Geometrias não Euclidianas na estrutura curricular do estado do Paraná. Treze professores apresentam algumas ideias e opiniões sobre as Geometrias não Euclidianas. Os resultados mostram que a inserção e o estudo das Geometrias não Euclidianas ainda não instauraram novas concepções, uma vez que somente oito professores apresentam suas concepções fundamentadas em resultados e/ou conceitos dessas Geometrias.
\end{abstract}

Palavras-chave: Geometrias não Euclidianas. Concepções de Geometrias. Formação de Professores. Educação Básica.

\begin{abstract}
Current research identified and analyzed the concepts of non-Euclidean geometries of a group of 27 primary school Math teachers who work in government schools in the state of Paraná, Brazil. Knowledge, opinions, preferences, and ideas on the geometries of the participants were verified. The participants were chosen through a questionnaire and data collection was retrieved from a half-structured interview. Six teachers did not provide any ideas on the subject matter and one male teacher was not aware of the inclusion of non-Euclidean geometries in the curriculum. Thirteen teachers presented some ideas and opinions on non-Euclidean geometries. Results show that the insertion and the study of non-Euclidean geometries have not introduced new concepts since only eight teachers provided concepts based on results and concepts of these geometries.
\end{abstract}

Keywords: non-Euclidean geometries. Concepts of geometries. Teacher formation. Primary teaching and education.

\footnotetext{
* Doutora em Educação para a Ciência e a Matemática pela Universidade Estadual de Maringá (PCM/UEM. Professora do Instituto Federal Catarinense - Campus Concórdia, Concórdia, Santa Catarina, Brasil. Endereço: Rodovia SC 283 - Km 08, Vila Fragosos, CEP: 89700-000, Concórdia, Santa Catarina, Brasil. E-mail: karla.lovis@ifc-concordia.edu.br.

** Doutor em Topologia Algébrica pela Universidade de São Paulo (ICMC/USP). Professor Associado do Departamento de Matemática e do Programa de Pós-graduação em Educação para a Ciência e a Matemática da Universidade Estadual de Maringá (PCM/UEM), Maringá, Paraná, Brasil. Endereço: Avenida Colombo, 5790, Jardim Universitário, Departamento de Matemática, CEP: 87020-900, Maringá, Paraná, Brasil. E-mail: vsfranco@uem.br.
} 


\section{Introdução}

O interesse pelo estudo das concepções dos professores a respeito das Geometrias não Euclidianas adveio da junção entre a história pessoal dos autores - acadêmica e profissional e o ensino de Geometrias. Nos últimos seis anos, temos nos dedicado a estudar as consequências da inserção de conteúdos de Geometrias não Euclidianas, que ocorreu em 2008, nas Diretrizes Curriculares da Educação Básica - DCE do estado do Paraná. Durante esses estudos, frequentemente percebia-se contradições, incertezas, opiniões e preferências dos professores sobre as Geometrias ${ }^{1}$.

As DCE é o documento oficial do estado do Paraná, responsável por nortear e recomendar os conteúdos e metodologias que podem ser empregados nos anos finais do Ensino Fundamental e no Ensino Médio. O Documento está divido em duas partes: na primeira, são exibidas algumas considerações sobre a Educação Básica e a opção pelo currículo disciplinar. A segunda parte trata de questões referentes à disciplina de Matemática, tais como: dimensão histórica da disciplina, fundamentos teórico-metodológicos, os conteúdos estruturantes, os encaminhamentos metodológicos e a avaliação. Quanto aos conteúdos estruturantes, eles são divididos em cinco: Números e Álgebra, Grandezas e Medidas, Geometrias, Funções e Tratamento da Informação.

O conteúdo Geometrias se desdobra nos seguintes: Geometria Plana, Geometria Espacial, Geometria Analítica e noções básicas de Geometrias não euclidianas. Quanto às Geometrias não Euclidianas, as DCE do Paraná recomendam, para o Ensino Fundamental trabalhar com "geometria projetiva (ponto de fuga e linhas do horizonte); Geometria topológica (conceitos de interior, exterior, fronteira, vizinhança, conexidade, curvas e conjuntos abertos e fechados) e noções de geometria dos fractais” (PARANÁ, 2008, p. 56).

No Ensino Médio as DCE recomendam apresentar aos estudantes noções de Geometrias não Euclidianas, ao abordar a Geometria dos Fractais, Geometria Projetiva, Geometria Hiperbólica e Geometria Elíptica². Com relação a essas Geometrias, as Diretrizes recomendam:

\footnotetext{
${ }^{1} \mathrm{O}$ termo Geometrias, neste texto, se refere a: Geometria Euclidiana, Geometria Hiperbólica, Geometria da Superfície Esférica, Geometria Projetiva, Geometria Fractal e Topologia.

${ }^{2}$ Nas DCE a Geometria da Superfície Esférica é chamada de Geometria Elíptica. Porém, ao descrever essa Geometria, percebe-se que as Diretrizes se referem, na verdade, à Geometria da Superfície Esférica, construída por Riemann. A Geometria Elíptica foi desenvolvida por Félix Klein, sendo que um de seus modelos é obtido por meio da identificação dos pontos antípodas da Superfície Esférica, gerando o que se denomina de Plano Projetivo. Nessa Geometria, o primeiro postulado de Euclides é verificado, e isso não ocorre na Geometria da Superfície Esférica.
} 
$\mathrm{Na}$ geometria dos fractais pode-se explorar: o floco de neve e a curva de Koch; triângulo e tapete de Sierpinski. Para abordar os conceitos elementares da geometria hiperbólica uma possibilidade é através do postulado de Lobachevsky (partindo do conceito de pseudoesfera, pontos ideais, triângulo hiperbólico e a soma de seus ângulos internos). Já na apresentação da geometria elíptica, fundamentá-la através do seu desenvolvimento histórico e abordar: postulado de Riemann; curva na superfície esférica e discutir o conceito de geodésia; círculos máximos e círculos menores; distância na superfície esférica; ângulo esférico; triângulo esférico e a soma das medidas de seus ângulos internos; classificação dos triângulos esféricos quanto a medida dos lados e dos ângulos; os conceitos referentes à superfície da Terra: pólos, equador, meridianos, paralelos e as direções de movimento (PARANÁ, 2008, p. 27-8).

Por fim, o documento expõe que esses conteúdos "são fundamentais para que o aluno do Ensino Médio amplie seu conhecimento e pensamento geométrico" (PARANÁ, 2008, p. 57).

Diante das recomendações das DCE e das experiências vivenciadas pelos pesquisadores, intensificou-se o interesse em investigar as concepções dos professores sobre as Geometrias. Portanto, a problemática desta pesquisa surge como o fruto de um período de interrogações, da procura de fundamentos teóricos e de reflexões sobre o tema concepções e das questões que envolvem as Geometrias.

Desse modo, este trabalho é o resultado de um estudo a respeito das concepções de vinte e sete professores de Matemática, pertencentes a vinte e sete diferentes Núcleos Regionais de Educação - NRE ${ }^{3}$ - do Estado do Paraná, sobre as Geometrias.

\section{Metodologia}

Para atingir o objetivo, realizou-se uma pesquisa qualitativa, cujo instrumento selecionador foi um questionário. Para a coleta de dados, especificamente, organizou-se uma entrevista semiestruturada e trinta e seis cartões que versam sobre as Geometrias.

Como o objetivo era entrevistar um professor de cada NRE, foi necessário criar alguns critérios para selecionar os professores que fariam parte da investigação. Nesse sentido, elaborou-se o questionário, que foi enviado no início de fevereiro de 2012, para os professores que atuam nas escolas públicas do estado do Paraná. O questionário continha tópicos e perguntas relacionadas a dados gerais sobre os professores. Também questionava se os professores ensinam as Geometrias e o que entendem por Geometrias. O questionário foi enviado para os e-mails oficiais de todos os professores do estado do Paraná, via Secretaria de

\footnotetext{
${ }^{3}$ O estado do Paraná possui 32 (trinta e dois) Núcleos Regionais de Educação.
} 
Educação, e as respostas foram encaminhadas para o e-mail de um dos pesquisadores.

Após a obtenção dos questionários respondidos, selecionou-se um professor de cada NRE para participar da entrevista. O critério utilizado para escolher os professores foi selecionar os professores que deram resposta à questão sobre o que eles entendem por Geometria Euclidiana e por Geometrias não Euclidianas. Destaca-se que professores de cinco Núcleos não aceitaram participar da entrevista ${ }^{4}$, portanto, os sujeitos da pesquisa são vinte e sete professores. As entrevistas foram realizadas nas cidades nas quais os professores residem; os horários e dias foram combinados entre um dos pesquisadores e o professor participante.

Antes de iniciar as entrevistas, elaborou-se um roteiro com onze tópicos e questões que versam sobre Geometrias. No entanto, ao elaborar o roteiro percebeu-se que era preciso algo a mais para identificar as concepções dos professores. Diante desse fato, foram confeccionados trinta e seis cartões com palavras, representações de entes geométricos e objetos relacionados com as Geometrias. Para elaborar os cartões, foram investigados os principais conceitos e resultados de cada Geometria e as considerações das DCE sobre as Geometrias não Euclidianas. A figura 1 retrata esses cartões.

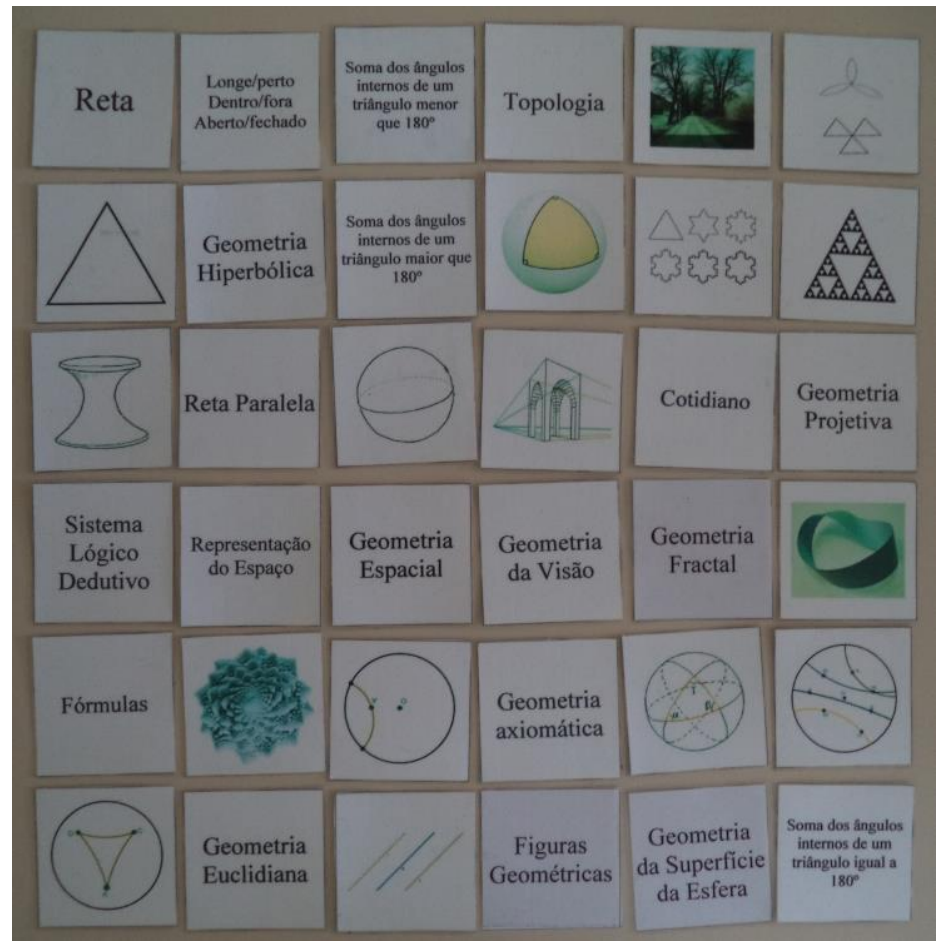

Figura 1- Cartões utilizados na pesquisa Fonte: autores

Os cartões foram utilizados no decorrer da entrevista, e a apresentação se deu da

\footnotetext{
${ }^{4}$ Dois professores alegaram que não poderiam participar da entrevista pela indisponibilidade de tempo. Os outros três não justificaram o motivo. Houve insistência por parte dos pesquisadores, porém, não se obteve êxito.
} 
seguinte forma: o pesquisador apresentava as questões da entrevista semiestruturada e, posteriormente, espalhava os cartões, de forma aleatória, sobre uma mesa. A seguir solicitava que os professores relacionassem aqueles que considerassem pertinentes, ou que escolhessem um ou mais cartões para comentar. Na ocasião, procurou-se deixar os professores à vontade, para que pudessem expressar seus conhecimentos, opiniões, ideias e preferências sobre as Geometrias.

Por fim, para analisar os dados obtidos, utilizou-se a análise de conteúdo descrita por Bardin (2007). Para desempenhar a análise, todas as entrevistas foram gravadas em vídeo e posteriormente transcritas. Após a transcrição, realizou-se a leitura flutuante dos documentos. Durante essa leitura definiu-se qual seria o corpus da análise, ou seja, "o conjunto dos documentos considerados e que seriam submetidos aos procedimentos analíticos" (BARDIN, 2007, p. 122). Surgiram, assim, as primeiras hipóteses do trabalho.

Destaca-se que, quando do início da pré-análise e da exploração do material, não tínhamos hipóteses pré-concebidas a respeito das concepções dos professores. A análise de conteúdo foi feita, como descreve Bardin (2007, p. 124), "às cegas”, ou seja, as hipóteses surgiram com a exploração do material. Após a leitura flutuante, surgiram alguns indicadores que foram imprescindíveis na exploração do material. Nessa fase, realizaram-se, novamente, várias leituras das transcrições, com o objetivo de codificar e construir as categorias.

De acordo com Bardin (2007, p. 129), a codificação diz respeito ao tratamento do material, e "corresponde a uma transformação - efetuada segundo regras precisas - dos dados em bruto do texto". Bardin (2007, p. 130-1) expõe, ainda, que para realizar uma análise de conteúdo é preciso obter uma unidade de registro e de contexto. No caso da pesquisa, a unidade de registro refere-se às concepções dos professores. As categorias foram construídas por meio de conjuntos de palavras ou de fragmentos das falas dos professores. Para estabelecer as categorias, foram observados os traços mais relevantes, as semelhanças, os contrastes e diferenças obtidos nas respostas dos professores.

\section{Os participantes da pesquisa e a formação em Geometrias}

Quanto aos participantes da pesquisa, todos são professores de Matemática que atuam em escolas públicas do estado do Paraná. Esses professores têm graduação em Matemática (treze professores), em Ciências com habilitação em Matemática (treze professores) e Ciências Biológicas com habilitação em Matemática (um professor). Todos, no momento da 
investigação, tinham pelo menos uma especialização, sendo que cinco já haviam participado do $\mathrm{PDE}^{5}$, quatro estavam participando do programa, dois eram mestres e cinco estavam cursando o Mestrado.

Quanto à formação em Geometrias não Euclidianas, somente um professor estudou Geometria Projetiva durante a graduação e outros dois comentaram que ouviram falar dessas Geometrias na graduação. Nenhum professor estudou ou ouviu falar das Geometrias não Euclidianas na Educação Básica. Após a graduação, quinze professores estudaram alguns conceitos e resultados das Geometrias não Euclidianas por meio de cursos oferecidos pela SEED $^{6}$, pelos NRE's e nos GTR's ${ }^{7}$. Oito professores conhecem alguns conceitos e resultados das Geometrias não Euclidianas, porque leram e estudaram a respeito do assunto, e quatro professores nunca estudaram as Geometrias não Euclidianas.

Dentre as cinco Geometrias não Euclidianas recomendadas pelas DCE, vinte e três professores já estudaram ou leram algo sobre a Geometria Fractal, seis professores sobre a Geometria Projetiva, quatro professores sobre a Geometria da Superfície da Esfera e dois professores sobre a Geometria Hiperbólica e a Topologia.

\section{Concepções: fundamentos teóricos}

Escolheu-se estudar as concepções, por acreditar que elas desempenham um papel importante na vida e na tomada de decisões dos professores. Cury (1994, p. 25) destaca que o interesse pelo estudo das concepções e crenças dos professores de Matemática sobre a disciplina e a influência que ela exerce na prática teve sua "origem no início do século $\mathrm{XX}$, a partir das preocupações dos psicólogos sociais que procuravam entender a influência das crenças sobre o comportamento das pessoas". A partir da década de 1980, o interesse pelo estudo das concepções e crenças intensificou-se entre os estudiosos de diversas áreas: psicólogos, cientistas políticos, antropólogos e educadores. Com o desenvolvimento da Educação Matemática, a preocupação com o ensino e aprendizagem desta disciplina, bem como o estudo das concepções, passou a ter destaque nos trabalhos dos Educadores Matemáticos, principalmente, nos Estados Unidos e em Portugal.

Embora utilizado por muitos pesquisadores, o termo concepção é polissêmico, e, nesse

\footnotetext{
${ }^{5}$ O PDE é o Programa de Desenvolvimento Educacional idealizado pela Secretaria do Estado do Paraná (SEED) que visa à formação continuada dos professores da Educação Básica do Estado.

${ }^{6}$ Secretaria do Estado da Educação do Paraná.

${ }^{7}$ Grupo de Trabalho em Rede.
} 
sentido, difícil de definir porque não apresenta um único significado. Ferreira ${ }^{8}$ (1998, p. 20) destaca que "atitudes, representações, valores, concepções e crenças apresentam características muito próximas, e, por vezes, mostram-se entrelaçados. Agrava a situação o fato de que muitas e diferentes entre si são as definições para cada um destes termos".

Um dos primeiros trabalhos cujo foco foi o estudo das concepções foi o da pesquisadora norte-americana Alba Thompson ${ }^{9}$ (1997). Thompson (1997) investigou as concepções de Matemática e de ensino de Matemática de três professoras da junior high school (equivalente a $4^{\mathrm{a}}$ série ou $5^{\mathrm{o}}$ ano do Ensino Fundamental) e analisou a relação entre as concepções das professoras e suas práticas pedagógicas. A pesquisadora observou que as professoras desenvolveram padrões de comportamentos que caracterizavam a sua prática pedagógica e, por isso, "podem ser manifestações de noções, crenças e preferências, conscientemente sustentadas" ou "podem ser crenças ou intuições, inconscientemente sustentadas, que podem ter evoluído fora da experiência do professor" (THOMPSON, 1997, p.12). Anos mais tarde, Thompson (1992) apresentou a seguinte definição para o termo concepções:

As concepções dos professores sobre a natureza da Matemática podem ser vistas como crenças conscientes e inconscientes, conceitos, significado, regras, imagens mentais e preferências relacionadas com a disciplina de Matemática. Essas crenças, conceitos, opiniões e preferências constituem os rudimentos de uma filosofia da Matemática, embora para muitos professores eles podem não serem desenvolvidas e relacionadas com uma filosofia coerente (THOMPSON, 1992, p. 132).

Assim, a definição de concepção apresentada por Thompson inclui as crenças, opiniões, conceitos, significados, regras, imagens mentais e as preferências dos professores. Tem-se, então, uma definição mais complexa de concepções, pois abarca um quadro de outras noções que constituem uma rede de representações dos docentes. Em outras palavras, compõem as crenças, as imagens mentais, as opiniões, as preferências; algumas, de dimensões mais elaboradas; outras, de dimensões mais superficiais.

Para o pesquisador português João Pedro Ponte (1992) o interesse pelo estudo das concepções dos professores, bem como de outros profissionais, baseia-se na hipótese de que o indivíduo possui uma base conceitual que determina o seu pensamento e as suas ações. Essa

\footnotetext{
${ }^{8}$ Ferreira (1998) em sua dissertação de Mestrado apresenta uma vasta revisão da literatura sobre o termo crença. A autora destaca trabalhos relacionados às crenças sobre a Matemática, seu ensino e aprendizagem, que envolvem professores e alunos.

9 O artigo de Alba Thompson foi originalmente publicado em 1984, na revista Educational Studies in Mathematics, com o título The Relationship of Teachers' Conceptions of Mathematics and Mathematics Teaching to Instructional Practice. Sua tradução para o português e sua publicação na revista Zetetiké aconteceu em 1997. Na sequência do trabalho, utiliza-se como referência o artigo traduzido e publicado em 1997.
} 
base conceitual "é de uma natureza diferente dos conceitos específicos - não diz respeito a objetos ou acções bem determinadas, mas antes constitui uma forma de os organizar, de ver o mundo, de pensar" (PONTE, 1992, p.1). Para o autor, as concepções atuam como uma espécie de filtro, ou seja, ajudam a estruturar o sentido que damos às coisas, mas também podem agir como um elemento bloqueador em relação a novas realidades ou problemas, limitando nossas possibilidades de ação e compreensão.

Ponte (1992) destaca que a criação e propagação das concepções estão relacionadas com contexto histórico, com a origem profissional (formação inicial e continuada, tanto no que se refere à parte científica quanto pedagógica) e com os aspectos sociais (expectativas dos alunos, pais e professores, administração escolar, currículo, entre outros). Para o autor, o estudo das concepções deve considerar a natureza do conhecimento, uma vez que são as concepções que ajudam a entender e compreender o mundo a nossa volta.

Outro pesquisador português que também discorreu sobre o termo concepções foi Henrique Guimarães (1988, 2003). Para ele, o estudo das concepções dos professores inserese em uma área reconhecida "como o estudo do pensamento ou do conhecimento do professor” (GUIMARÃES, 2003, p. 4); e esclarece que conhecer as concepções do professor é ter acesso à sua "“vida mental' [...] conhecer e compreender os vários aspectos do seu pensamento e conhecimento, bem como as relações desses aspectos com a atuação ou comportamento".

Para o termo concepção, na pesquisa de doutorado, o autor descreve que as concepções são um instrumento do pensar e expõe que, à luz da noção de concepção, pode-se associar um sentido de construção ou criação de algo,

[...] num acto onde concorrem elementos interiores (da pessoa) e elementos exteriores (da coisa). Este acto de conceber cujo culminar pode ser visto como uma espécie de 'dar a luz', é no entanto sempre interior, significando este 'dar a luz' que a concepção ficou disponível para os 'olhos' (do pensamento) da pessoa (GUIMARÃES, 2003, p. 47-8).

Dos trabalhos de pesquisadores brasileiros que buscaram compreender o termo concepção, destaca-se o da pesquisadora Helena Cury (1994) que, após fazer uma revisão da literatura sobre os termos crenças e concepções, optou pelo termo concepções por acreditar que ele "engloba toda a filosofia particular de um professor" (CURY, 1994, p.37, grifo autor). A pesquisadora destaca a importância das influências, dos professores formadores e dos colegas, na formação do sistema de crenças dos professores a respeito da Matemática. Para a autora, "as idéias veiculadas pela cultura matemática, a partir das principais correntes filosóficas da Matemática, disseminam-se entre os matemáticos, entre os autores de livros- 
textos, entre os pesquisadores em Educação Matemática, entre os responsáveis pelos currículos dos cursos de Licenciatura" (CURY, 1994, p. 33). Na citação a seguir, encontra-se a conceituação para o termo concepção, dada por Cury,

\begin{abstract}
Acreditamos que os professores de Matemática formam idéias sobre a natureza da Matemática, ou seja, concebem a Matemática, a partir das experiências que tiveram como alunos e professores, do conhecimento que construíram, das opiniões de seus mestres, enfim, das influências sócio-culturais que sofreram durante suas vidas, influências essas que se vêm formando ao longo dos séculos, passando de geração a geração, a partir das idéias de filósofos que refletiram sobre a Matemática (CURY, 1994, p. 37, grifo autor).
\end{abstract}

Por fim, recorre-se também ao Novo Dicionário de Língua Portuguesa. Ferreira (1986, p. 445) expõe que concepção é "o ato de conceber ou criar mentalmente, de formar ideias, especialmente abstrações; noção, ideia, conceito, compreensão; modo de ver, ponto de vista; opinião, conceito". A definição apresentada pelo Novo Dicionário de Língua Portuguesa engloba a maioria dos termos usados pelos pesquisadores descritos anteriormente.

Diante do exposto, entende-se o termo concepções como os conhecimentos, as opiniões, as preferências e as ideias que os professores apresentam. Portanto, neste trabalho, investigar as concepções dos professores implicará averiguar os conhecimentos, as opiniões, as preferências e as ideias que os participantes desta pesquisa apresentam a respeito das Geometrias.

\title{
5 Concepções sobre as Geometrias não Euclidianas
}

A história das Geometrias não Euclidianas está atrelada ao quinto postulado de Euclides, o postulado das paralelas. Alguns matemáticos tentaram demonstrar que o quinto postulado era um teorema dedutível dos quatros primeiros postulados, além das definições e dos axiomas. Outros, ao longo dos séculos, tentaram eliminar o quinto postulado do sistema euclidiano. Houve, também, aqueles que tentaram mostrar que o quinto postulado poderia ser substituído por algum princípio mais simples e mais evidente (BARKER, 1969 p. 47-8).

Foi, no entanto, a negação do quinto postulado de Euclides que desencadeou a construção de novas Geometrias. As Geometrias não Euclidianas, por exemplo, são assim chamadas porque não estão de acordo com, pelos menos, um dos cinco postulados de Euclides.

Pela sua história, quando se faz referencias às Geometrias não Euclidianas, em geral, refere-se à Geometria Hiperbólica e à Geometria Elíptica - cujos postulados negam ou abandonam alguns dos postulados de Euclides - mas, após a observação de que existem 
outras Geometrias que não satisfazem um ou mais postulados dos Elementos de Euclides, foi adotado, neste trabalho, o critério de designá-las, também, de não Euclidianas.

Lobachevsk iniciou a construção da Geometria Hiperbólica. Este matemático rejeitou somente o quinto postulado de Euclides, mas conservou os demais, bem como os axiomas da Geometria Euclidiana. Os matemáticos Felix Klein (1849-1925) e Henri Poincaré (18641912) criaram modelos para a Geometria Hiperbólica. Na Geometria Hiperbólica, é possível obter, por um ponto fora da reta, mais de uma reta paralela à reta dada. Uma das consequências desse resultado é que a soma das medidas dos ângulos internos de um triângulo é menor que dois retos.

Apesar do nome Geometria Elíptica constar nas DCE do Estado do Paraná, espera-se que seja trabalhada, na Educação Básica, a Geometria da Superfície da Esfera. A Geometria Elíptica, particularmente, provém da Geometria da Superfície Esférica, mas é um pouco mais elaborada, conforme foi observado na nota de rodapé número 5. Foi nesse sentido que esta pesquisa foi pensada, ou seja, ela trata das concepções dos professores em relação à Geometria da Superfície da Esfera, e não da Geometria Elíptica.

Após a construção da Geometria Hiperbólica, Riemann (1826-1866) construiu a Geometria da Superfície da Esfera. Nessa Geometria, o primeiro postulado (dois pontos determina uma reta), o segundo (um segmento de reta pode ser prolongado) e o quinto postulados (dada uma reta e um ponto fora dela é possível traçar por este ponto uma única reta paralela a reta dada) de Euclides não são válidos. Na Geometria da Superfície da Esfera, não temos retas paralelas, pois dada uma reta qualquer e ponto fora desta reta, sempre existirá uma reta que passa por esse ponto e intercepta a reta dada. Um resultado importante da Geometria da Superfície da Esfera refere-se à soma das medidas dos ângulos internos de um triângulo, que sempre será maior do que $180^{\circ}$.

A Geometria Projetiva surgiu antes da Geometria Hiperbólica, porém só foi considerada uma Geometria não Euclidiana anos mais tarde. $\mathrm{O}$ desenvolvimento da Geometria Projetiva está atrelado ao desenvolvimento da perspectiva. Essa Geometria é o estudo das propriedades descritivas das figuras geométricas e, em termos axiomáticos, uma das diferenças entre a Geometria Euclidiana e a Geometria Projetiva está na inexistência de retas paralelas. Nessa Geometria, as retas se encontram na linha do horizonte, ou linha no infinito, ou ainda, reta imprópria, que contém os pontos de fuga, ou pontos no infinito, ou pontos impróprios. Essa Geometria também não se preocupa com as propriedades métricas de seus objetos e sua axiomática é diferente daquela adotada pela Geometria Euclidiana. 
O início da Topologia pode ser creditado ao estudo do problema das sete pontes de Königsberg. A topologia estuda as questões qualitativas dos objetos e não quantitativas. Alguns exemplos básicos de conceitos topológicos são as noções de vizinhança, de interior e exterior, de aberto e fechado, de conexo e desconexo, de contínuo e descontínuo, de orientação de espaços, entre outros. Nota-se que a maioria desses conceitos são percebidos e compreendidos, intuitivamente, pelas crianças antes mesmo da compreensão de conceitos da Geometria Euclidiana.

A Geometria Fractal, por outro lado, está associada à autossimilaridade, à dimensão e à complexidade infinita dos objetos e teve seu início com Benoit Mandelbrot. Fenômenos e figuras encontradas na natureza são explicadas de forma mais satisfatórios pela Geometria Fractal do que pela Geometria Euclidiana. Na Topologia e na Geometria Fractal, também são abandonados os postulados de Euclides.

Diante das leituras sobre as Geometrias não Euclidianas e das recomendações expostas pelas DCE, nos propomos a investigar as concepções dos professores a respeito desses conteúdos. Na sequência, seguem as categorias encontradas e excertos das falas, de alguns dos participantes da pesquisa e a análise.

Durante a investigação foi possível obter três categorias referentes às concepções dos professores a respeito das Geometrias não Euclidianas:

1. professores que não apresentam concepções a respeito dessas Geometrias;

2. professores que apresentam algumas ideias e opiniões;

3. professores que expõem suas concepções por meio de resultados e/ou conceitos das Geometrias não Euclidianas.

Constatou-se que seis professores não apresentam uma concepção sobre as Geometrias não Euclidianas. Dentre esses, quatro professores nunca haviam estudado essas Geometrias, sendo que uma das participantes da pesquisa não sabia da inclusão das Geometrias não Euclidianas nas DCE do Paraná. Segue o comentário da professora P01:

[...] essas que são (...) o que exatamente? Eu não to (sic) lembrada [...] os fractais eu até vi um vídeo [...] mas ele não entra no nosso currículo, a gente não trabalha [...] se você pegar a nossa Diretriz ele nem cita [...] eu não sei se você chegou ir em algum lugar que eles estão trabalhando no Paraná? (Professor P01, entrevista 10, 2012).

Antes de iniciar a pesquisa, acreditava-se que seria praticamente impossível encontrar algum professor de Matemática, atuante nas escolas públicas do Estado do Paraná, que não tivesse conhecimento da inclusão desse conteúdo nas Diretrizes. Essa hipótese decorria do fato de que as DCE consistem no documento oficial que norteia e recomenda os conteúdos e 
metodologias que devem ser aplicadas nas salas de aula das escolas públicas do Estado e, também, pelo fato das reformulações das DCE terem sido debatidas em processo de discussão coletiva $^{10}$. O caso dessa professora nos faz pensar sobre a dificuldade da divulgação, da implementação e da utilização de uma estrutura curricular.

Dois professores dessa categoria, apesar de terem lido ou estudado sobre o assunto não apresentaram, mediante as análises dos meios utilizados para a pesquisa, uma concepção sobre o assunto, como se exemplifica com a fala da professora P02, na qual não se identifica uma concepção de Geometria não Euclidiana: “[...] parece que é uma coisa redonda [...] essa Geometria parece que só vai ter coisas redondas nela. [...] essa Geometria aqui da não Euclidiana [...] quando eu penso nela parece que tudo é redondo [...] não sei por que, mas na minha cabeça passa isso".

Da segunda categoria, temos treze professores que apresentaram suas concepções por meio de algumas ideias e opiniões a respeito das Geometrias não Euclidianas. Com o objetivo de compreender melhor os elementos discursivos que levaram a essa categorização, são citados a seguir, com breves análises, algumas das respostas dadas por alguns participantes da pesquisa. Segue o comentário de P03:

A não Euclidiana a gente tem as esferas, Fractal e por aí [...] eu sei que tem algumas curvas [...] a gente trabalha hoje com a Euclidiana. Essa aqui (não euclidiana) a gente tem noção assim, passo mais ou menos. Mas a gente trabalha com a Euclidiana mesmo, a gente não trabalha com as não Euclidianas. (Professor P03, entrevista 14, 2012).

Observa-se que essa professora entende que as Geometrias não Euclidianas estão relacionadas a diferentes planos, esferas e curvas, talvez pensando na Geometria da Superfície Esférica. A frase final demonstra que P03 sabe da inclusão das Geometrias não Euclidianas nas DCE do Paraná, mas afirma categoricamente que não trabalha com essas Geometrias com seus alunos. Percebeu-se, em outros momentos da entrevista, que essa professora tinha algumas ideias de Geometria Fractal, mas não soube explicar, mesmo que informalmente, algum conceito ou resultado dessa Geometria. Além disso, ela comentou que reta paralela está relacionada somente com a Geometria Euclidiana e que não comentaria com seus alunos o resultado sobre retas paralelas da Geometria Hiperbólica, por exemplo.

Quando questionado sobre o que responderia a um aluno que o perguntasse sobre o

\footnotetext{
${ }^{10}$ Segundo Paraná (2008, p. 8), as DCE passaram por reformulações, que foram debatidas em processo de discussão coletiva, no período de 2004 a 2008. O documento expõe que os professores que atuavam na Educação Básica do Estado durante esse período, participaram da reformulação das Diretrizes. Ainda em 2007 e 2008 , as Diretrizes Curriculares Estaduais passaram por leituras críticas de especialistas nas diversas disciplinas e em história da educação. Tais leitores, vinculados a diferentes universidades brasileiras, participaram, também, de debates presenciais com as equipes disciplinares do DEB, com vistas aos necessários ajustes finais dos textos.
} 
que é uma Geometria não Euclidiana, o professor P04 deu a seguinte resposta:

[...] eu tentaria dar exemplos do que Euclides fez, o que ele usou nos seus Elementos e o que veio depois com essa Geometria não Euclidiana era fugir, a gente conseguir observar algo, enxergar algo que não está visível naquele momento". Afirma ainda que "é difícil para um professor caracterizar que um triângulo pode ser maior ou menor do que $180^{\circ}$. Por que daí ele fala: nossa, mas eu sempre vi assim (...) existe, claro que existe, mas existe outro tipo também. Dificilmente você encontra um professor que trabalha isso daqui (Professor P04, entrevista 2, 2012).

Infere-se, por meio dessa fala, que o professor P04 acredita que as Geometrias não Euclidianas são Geometrias que foram construídas, porque a Geometria Euclidiana não era suficiente para observar algo, enxergar algo que não está visível naquele momento. Porém, sabe-se que a primeira Geometria não Euclidiana, aceita como tal, foi a Geometria Hiperbólica, que foi construída teoricamente a partir da negação da unicidade de reta paralela a uma reta dada, passando por um ponto fora dela, e não por necessidade de enxergar algo não visível por meio da Geometria Euclidiana.

Para a frase - é difícil para um professor caracterizar que um triângulo pode ser maior ou menor do que $180^{\circ}$ - têm-se duas hipóteses: a primeira é que P04 não sabe que o que dá $180^{\circ}$ é a soma das medidas dos ângulos internos de um triângulo, e não que um triângulo é maior que $180^{\circ}$. A segunda hipótese, e talvez a mais provável, seja a pouca importância que se dá ao expressar conceitos geométricos utilizando a linguagem Matemática, que é uma das mais importantes representações semióticas da Matemática. Além disso, P04 destaca que é difícil encontrar professores que trabalhem a diferença existente sobre a soma das medidas dos ângulos internos de um triângulo na Geometria Euclidiana, na Hiperbólica e na Esférica, e a hipótese muito provável é que isso esteja, de fato, acontecendo no ensino das Geometrias.

Outro professor que apresenta algumas ideias e opiniões em relação às Geometrias não Euclidianas é a professora P05, segue o recorte da sua fala: “[...] eu poderia falar assim das paralelas, dos meridianos [...] e também que ela tá (sic) muito envolvida com o computador, e iria praticar com o computador; assim a mão seria praticamente, seria difícil aqueles gráficos bem complicados".

Além disso, quando P05 é apresentada à palavra Topologia, comenta que: “[...] o que eu entendo de Topologia, mais ou menos, é uma Geometria que foi, tipo assim, fotografada lá de cima, uma visão assim maior".

Para completar, P05 afirma que:

[...] eu tinha conhecimento que a Geometria não Euclidiana era só a Hiperbólica. Não imaginava que Fractais, Projetiva e Topologia fosse Geometria não Euclidiana. Isso aqui (Fractais) eu só via ligação com artes. Inclusive assim, só pra boniteza; só coisa que já vem pronta da natureza ou alguém que construía pra fazer um quadro. Geometria Projetiva pra (sic) mim tinha a ver com desenho geométrico, com a parte de desenho (Professor P05, entrevista 3, 2012). 
Para a professora P05, as Geometrias não Euclidianas estão relacionadas aos paralelos e meridianos e envolvem o computador. Porém, P05 não soube explicar de que modo elas estão relacionados com paralelos e meridianos. Também comentou que só conseguiria trabalhar com essas Geometrias se o estudo fosse feito no computador e que, para ela, Fractais, Geometria Projetiva e Topologia não eram Geometrias não Euclidianas, e que Fractais só tinha aplicação na Arte, sendo utilizados pela questão da beleza. Essa observação, por sua vez, nos coloca diante de um fato: será que a professora leu as DCE, já que lá são citadas como Geometrias não Euclidianas todas as outras Geometrias tratadas na pesquisa? Outro elemento interessante dessa frase é: como será que essa professora conheceu a palavra Geometria Hiperbólica, classificando-a como não Euclidiana? Quando questionada sobre o que chamou sua atenção nas Geometrias não Euclidianas, ela comentou que nada chamou sua atenção e que ela somente havia feito, durante a graduação, um trabalhinho sobre Lobachevsky.

Em relação à Topologia, a participante P05 a confunde com a palavra Topografia, uma vez que ela afirma que a Topologia é "uma Geometria que foi, tipo assim, fotografada lá de cima, uma visão assim maior", que não tem relação com conceitos topológicos descritos anteriormente, e sim, com acidentes geográficos, que podem ser obtidos por meio de fotos para estudar suas situações e localizações.

Na sequência é dado mais um exemplo de uma professora, P06, que apresenta algumas ideias e opiniões em relação às Geometrias não Euclidianas:

Foi uma Geometria que veio primeiro de uma necessidade de novos estudos. Houveram ( sic) momentos na história em que a Geometria Euclidiana já não satisfazia mais (...) em, por exemplo, cálculo de curvas, até na teoria da relatividade, coisas assim. Então houve a necessidade de uma nova Geometria que estudasse essas coisas, curvas, hipérboles (Professor P06, entrevista 6, 2012).

P06 ainda fez o seguinte comentário: "É preciso ficar tudo bem definido da Geometria Euclidiana pra (sic) eu saber o que não é dela. Isso que você fala faz sentido: por que a gente não trabalha; tem a questão do professor não estar dominando? Tem; e tem a questão assim, é tanto conteúdo".

Para a professora P06, a Geometria Euclidiana não satisfazia mais e, por isso, surgiram as Geometrias não Euclidianas para auxiliar no cálculo de curvas, até na teoria da relatividade. A professora P06 acredita que as Geometrias não Euclidianas são Geometrias que foram construídas, por que a Geometria Euclidiana não era suficiente para resolver alguns problemas do cotidiano. A professora P06 destacou a importância do conhecimento da Geometria Euclidiana para conseguir compreender e trabalhar com as Geometrias não Euclidianas. Citando Poincaré, temos: 


\begin{abstract}
No espaço, conhecemos triângulos retilíneos dos quais a soma dos ângulos é igual a dois ângulos retos; mas conhecemos igualmente triângulos curvilíneos dos quais a soma dos ângulos é menor que dois ângulos retos. A existência de uns não é mais duvidosa que a dos outros. Dar aos lados dos primeiros o nome de retas é adotar a geometria euclidiana; dar aos lados dos últimos o nome de retas é adotar a geometria não euclidiana. Assim, perguntar que geometria convém adotar é perguntar a que linha convém dar o nome de reta (POINCARÉ, 1995, p. 41).
\end{abstract}

Em outras palavras, é possível estudar outras Geometrias sem conhecer a Geometria Euclidiana, mas a história nos apresentou primeiramente a essa Geometria e, assim, aparentemente, todas as outras estão baseadas nela, o que não é verdade, pois, por exemplo, não há modelos da Topologia e os principais exemplos da Geometria dos Fractais não são fundamentados na Geometria Euclidiana, mas, sim, nasce utilizando espaços topológicos.

Mas a frase - é preciso ficar tudo bem definido o que é da Geometria Euclidiana pra (sic) eu saber o que não é dela - é bastante importante, pois aponta uma observação que se tem feito, em relação à preocupação de muitos professores em querer conhecer melhor a Geometria Euclidiana, para poder compreender melhor o que não faz parte dessa Geometria.

Por meio dos dados obtidos, percebe-se que as concepções da maioria dos professores é fundamentada em suas opiniões, ideias e preferências a respeito das Geometrias. Em geral, não são fundamentadas nos conceitos e resultados sobre as Geometrias. Também, observou-se que elas foram construídas, principalmente, no decorrer de cursos oferecidos pela SEED e pelos Núcleos Regionais de Educação do estado do Paraná. A maioria dos professores já ouviu falar, principalmente dos Fractais, por meio desses cursos. No entanto, acredita-se, os estudos realizados nos cursos não foram suficientes para integrar os conteúdos não euclidianos às suas concepções. Esses novos conteúdos podem ter criado uma instabilidade intelectual, mas não foram suficientes para produzir uma nova concepção.

Oito professores apresentaram suas concepções por meio de resultados ou conceitos das Geometrias não Euclidianas. Destacam-se as falas de quatro professores, que são seguidas de comentários. Para o professor P07

[...] tem aquela, aquela famosa lá do, do postulado das paralelas né? Então, a Geometria não Euclidiana quebra esse postulado. Então, por causa das retas se encontrarem no infinito, sob perspectiva, é uma coisa que você pode quebrar. A questão das curvas né, quebra muito do que você estuda na plana (Professor P07, entrevista 11, 2012).

Para o professor P07, as Geometrias não Euclidianas estão relacionadas com curvas, com a quebra do quinto postulado e, por isso, as retas se encontrariam no infinito. Ao mencionar a quebra do quinto postulado, $\mathrm{P} 07$ está se referindo à negação do quinto postulado. Acredita-se que, ao mencionar que as retas se encontram no infinito, está aludindo ao fato de 
que na Geometria Projetiva, não existem retas paralelas e, ao mencionar a questão das curvas, refere-se à Geometria da Superfície da Esfera.

Outro participante que expôs suas concepções por meio de resultados e conceitos das Geometrias não Euclidianas foi a professora P08:

\begin{abstract}
Se for apenas para diferenciar, eu diria que a Geometria Euclidiana é a Geometria que trabalha com os planos e existem outras Geometrias que estudam outras figuras. Por exemplo, nosso planeta, ele não é um plano, então existe uma outra Geometria que trabalha com ele; na Geometria Euclidiana duas retas não se encontram, na Geometria que nós vemos, se você vê uma estrada as duas retas, que no caso são o meio fio, lá na frente elas vão se encontrar. Essa é uma outra Geometria que difere um pouco. A Geometria Fractal que trabalha mais com a realidade, com os formatos das montanhas que não são feitas de figuras perfeitas (Professor P08, entrevista 12, 2012).
\end{abstract}

Na opinião da professora P08 a diferença entre a Geometria Euclidiana e as não Euclidianas está pautada no fato de que em outras Geometrias existem outros planos, diferentes do euclidiano, como se observa na frase nosso planeta, ele não é um plano, então existe uma outra Geometria que trabalha com ele. Cita, também, mesmo que indiretamente, a Geometria Projetiva, quando afirma que se você vê uma estrada as duas retas, que no caso são o meio fio, lá na frente elas vão se encontrar. Cabe ressaltar, aqui, a frase: na Geometria Euclidiana, duas retas não se encontram. Provavelmente, o que a professora quis dizer aqui é que, nessa Geometria, as retas paralelas não se encontram. Novamente, destaca-se a importância da linguagem apropriada. Apesar, evidentemente, que alguns professores não se sentem à vontade diante de uma câmera. Quanto ao comentário - a Geometria Fractal que trabalha mais com a realidade, com os formatos das montanhas que não são feitas de figuras perfeitas - percebe-se a concepção segundo a qual, com Geometria Fractal, é possível analisar e dar respostas mais satisfatórias para as questões da natureza do que com a Geometria Euclidiana. A seguir destaca-se a fala de mais uma professora, P09:

Eu sempre parto do postulado das paralelas, que historicamente tinham os postulados e que o povo começou a desconfiar daquele tal do postulado e que aí, a partir disso, se desenvolveu outros tipos de Geometria, no qual as paralelas podem ter um ponto em comum lá no infinito. E também a questão do fractal, a questão das dimensões: dimensão finita, dimensão inteira, dimensão decimal, por exemplo (Professor P09, entrevista 16, 2012).

Segundo a professora P09, as Geometrias não Euclidianas surgiram de uma mudança no postulado das paralelas. Aliás, a frase responsável por levar a essa conclusão merece ser comentada, pois P09 afirma que historicamente tinham os postulados e que o povo começou a desconfiar daquele tal do postulado. Ao comentar que o povo começou a desconfiar tem-se como hipótese que P09 está se referindo aos matemáticos que buscaram entender o postulado das paralelas. Essa professora também utiliza uma frase bastante comum que apareceu nesta pesquisa, e também nas pesquisas de Santos (2009) e Carli (2012): as paralelas podem ter um 
ponto em comum lá no infinito. Nesse caso, está se referindo, na verdade, ao ponto de fuga acrescentado na Geometria Projetiva. A professora P09 também comentou que nos Fractais nos deparamos com figuras com diferentes dimensões. Por fim, salienta-se a fala da professora P10:

É um pouco difícil dar uma resposta assim rápida, mas eu posso dizer pra (sic) eles que é uma
Geometria que não segue a de Euclides, porque ela pertence a espaços curvos. O Euclides imaginava
que a Terra fosse achatada, era a visão daquela época. Eles não tinham a ideia da curvatura da Terra.
Então, tudo que se via na superfície da Terra era imaginado como plano. E aí, com o desenvolvimento
das Ciências, provou-se que a Terra era curva, lei da gravidade, as leis de Newton, algumas delas caíram
com relação às de Einstein, e criou-se ideias de novas Geometrias. E tem o quinto postulado, que foi
aonde deu a ruptura, onde surgiu a oportunidade de se criar novas Geometrias. Eles não conseguiram
provar o quinto postulado com base nos outros postulados. Aquela coisa que por um ponto fora de uma
reta só tem uma reta paralela isso cai por terra na Geometria, por exemplo, esférica. Que aí vai ter uma
infinidade. Aí muda muita coisa (Professor P10, entrevista 19, 2012). O professor P10 conhecia conceitos e resultados de todas as Geometrias não Euclidianas apresentadas, mas com alguns problemas conceituais. Por exemplo, P10 expôs que as Geometrias não Euclidianas estão relacionadas aos espaços curvos, mas o que é espaço curvo? Outro problema é com a frase: aquela coisa que por um ponto fora de uma reta só tem uma reta paralela isso cai por terra na Geometria, por exemplo, esférica. Que aí vai ter uma infinidade. Na Geometria da Superfície da Esfera, não existem retas paralelas. Quanto à Geometria Fractal, P10 afirma: você pode ter um polígono com infinitos lados e comprimento finito. A hipótese, nesse caso, é de que para o professor P10 os polígonos continuam existindo nessa Geometria, só que agora eles podem ter infinitos lados e comprimento finito. P10 também expressa um pouco de conhecimento de Topologia, como pode ser observado na frase: as ideias da Topologia [...] na faixa não tem dentro e fora [...] a ideia de dentro e fora não faz sentido. Provavelmente, ele está se referindo à faixa de Möbius, mas, na Topologia, os conceitos de interior e exterior são fundamentais, mas de fato, na faixa de Möbius, não faz sentido falar de dentro e fora.

Ressalta-se, aqui, a importância de um participante fazer vários comentários, uma vez que é possível observar com mais clareza as suas concepções. Observem a frase: a Geometria Euclidiana é excelente, para um universo pequeno; se você for estudar um universo maior, você vai ver que ela é insuficiente. A hipótese é que, para esse professor, as Geometrias não Euclidianas têm sua importância no estudo de objetos de dimensão (tamanho) muito grandes. Talvez, isso venha da relação que existe entre a Geometria da Superfície da Esfera e a Superfície da Terra. De fato, nesse caso, localmente, não se percebe a curvatura da Esfera e a Geometria Euclidiana pode ser explorada localmente, como se ela fosse plana no sentido euclidiano. Mas, outras Geometrias não Euclidianas não se preocupam com as questões 
métricas, como é o caso, por exemplo, da Geometria Projetiva ou da Topologia.

Diante dos dados obtidos, destaca-se que ao investigar as concepções dos professores, buscava-se saber, de um modo geral, o que os professores pensam sobre as Geometrias não Euclidianas. Na verdade, pretendia-se ter acesso ao pensamento do professor, ou como diz Guimarães (2003, p. 4) à sua "vida mental [...] em conhecer e compreender os vários aspectos do seu pensamento e conhecimento". Diante das concepções obtidas, observa-se que elas são, em sua maioria, fundamentadas em opiniões, preferências e ideias sobre as Geometrias. Nesse sentido, tudo indica os professores estão na fase de identificação dos conceitos não euclidianos, ou seja, eles ainda não integraram os conhecimentos não euclidianos às suas concepções.

No entanto, sejam as concepções sobre as Geometrias, pautadas em conhecimentos ou não, opiniões ou preferências, formadas e mantidas por meio das experiências vividas e/ou assimiladas nos cursos de graduações, de pós-graduações ou em cursos de formação, acreditase que elas são apresentadas no cotidiano da sala de aula.

\section{Considerações finais}

Estudar as concepções dos professores é, segundo Ponte (1992), fazer antropologia na nossa própria cultura; trata-se de um esforço particularmente difícil, tanto pelo objeto de estudo quanto pelo fato de o investigador estar inserido na mesma cultura que o investigado. Ponte (1992, p. 34) expõe que as pessoas raramente sentem-se à vontade para expor "as partes mais íntimas do seu ser”, bem como em expressar as suas concepções, particularmente, àquelas que não estamos habituados a pensar reflexivamente.

Nesta investigação, o termo concepção foi entendido como o conjunto de conhecimentos, opiniões, preferências e ideias que os professores possuem a respeito das Geometrias não Euclidianas. Salientamos que a esses aspectos somam-se às opiniões dos professores sobre a Matemática como disciplina, sobre seu ensino e aprendizagem, sobre seu papel como professores de Matemática e sobre o aluno como aprendiz.

No que se refere às concepções sobre as Geometrias não Euclidianas, obtivemos três categorias: 1) professores que não apresentam concepções a respeito dessas Geometrias; 2) professores que apresentam algumas ideias e opiniões; 3) professores que expõem suas concepções por meio de resultados e/ou conceitos das Geometrias não Euclidianas.

$\mathrm{Na}$ categoria 1, encontram-se professores que desconhecem as Geometrias não 
Euclidianas e professores que já ouviram falar sobre o assunto, porém ainda não construíram uma concepção a respeito. Os professores da categoria 2 apresentam algumas ideias e opiniões a respeito das Geometrias não Euclidianas. Nota-se, assim, que os professores conhecem pouco os fundamentos teóricos das Geometrias não Euclidianas constantes na DCE. Cabe destacar que a maioria dos professores ainda não integrou os conteúdos não euclidianos às suas concepções. Grande parte dos professores que compõem essa categoria estudou Geometrias não Euclidianas em cursos oferecidos pela SEED ou pelos NRE's, contudo, esses cursos não foram suficientes para instaurar novas concepções e reflexões acerca do conhecimento geométrico. Tudo indica que o estudo dos conteúdos não euclidianos não foi suficiente para produzir uma nova concepção. Acredita-se que se trata, portanto, de concepções em formação. Os professores da categoria 3 já apresentam noções que se aproximam da teoria das Geometrias não Euclidianas. Eles usaram conceitos e/ou resultados dessas Geometrias para expressar suas concepções.

Apesar das concepções observadas, defende-se a inclusão do tópico noções de geometrias não-euclidianas nas DCE, uma vez que essa inclusão estimulou, ainda que insatisfatoriamente, o estudo das Geometrias e promoveu, inclusive, uma reflexão sobre a própria Geometria Euclidiana, além de mostrar que a Geometria Euclidiana não é a única Geometria que existe. Nossa hipótese - mas que necessita de outras pesquisas - é a de que as concepções sobre as Geometrias foram e estão sendo alteradas e formadas com a inclusão das novas Geometrias na Educação Básica.

Por fim, salienta-se que identificar, descrever e analisar as concepções dos professores é uma condição indispensável para transformar o cenário do ensino de Geometrias.

\section{Referências}

BARDIN, L. Análise de Conteúdo. Lisboa: Edições 70, 2007.

BARKER, S. F. Filosofia da Matemática. Tradução: Leonidas Hegenberg e Octanny S. da Mota. Rio de Janeiro: Zahar Editores, 1969.

CARLI, F. A. R. de. A aprendizagem de Geometrias não Euclidianas: um estudo realizado com alguns professores da pública de ensino. 2012. 145 f. Dissertação (Mestrado em Educação para a Ciência e a Matemática) - Programa de Pós-graduação em Educação para a Ciência e a Matemática, Universidade Estadual de Maringá, Maringá, 2012.

CURY, H. N. As concepções de Matemática dos professores e suas formas de considerar os erros dos alunos. 1994. 275 f. Tese (Doutorado em Educação) - Faculdade de Educação, Universidade Federal do Rio Grande do Sul, Porto Alegre, 1994.

FERREIRA, A. C. O desafio de ensinar - aprender matemática no noturno: um estudo das crenças 
dos estudantes de uma escola pública de Belo Horizonte. 1998. 168 f. Dissertação (Mestrado em Educação) - Programa de Pós-graduação em Educação, Universidade Estadual de Campinas, Campinas, 1998.

FERREIRA, A. B. de H. Novo dicionário da língua portuguesa. 2. ed. Rio de Janeiro: Nova Fronteira, 1986.

GUIMARÃES, H. M. Ensinar Matemática: concepções e práticas. 1988. 290 f. Dissertação (Mestrado em Educação) - Faculdade de Ciências, Universidade de Lisboa, Lisboa, 1988.

GUIMARÃES, H. M. Concepções sobre a Matemática e a actividade Matemática: um estudo com matemáticos e professores do ensino básico e secundário. 2003. 431 f. Tese (Doutorado em Educação) - Faculdade de Ciências, Universidade de Lisboa, Lisboa, 2003.

PARANÁ, Secretaria de Estado da Educação. Diretrizes Curriculares de Matemática para a Educação Básica. Curitiba: Secretaria de Estado de Educação, 2008. 81 f.

POINCARÉ, H. O valor da Ciência. Tradução: Maria Helena F. Martins. Rio de Janeiro: Contraponto, 1995.

PONTE, J. P. Concepções dos Professores de Matemática e Processos de Formação. Educação Matemática: Temas de investigação. Universidade de Lisboa. Lisboa: Instituto de Inovação Educacional, 1992.

SANTOS, T. S. A Inclusão das Geometrias Não-Euclidianas no Currículo da Educação Básica. 2009. 138 f. Dissertação (Mestrado em Educação para a Ciência e o Ensino de Matemática) Programa de Pós-Graduação em Educação para a Ciência e a Matemática, Universidade Estadual de Maringá, Maringá, 2009.

THOMPSON, A. Teachers' beliefs and conceptions: a synthesis of the research. In: GROUWS, A. (Org.). Handbook of research in mathematics teaching and learning. New York: Macmillan, 1992. p. 127-146.

THOMPSON, A. A relação entre concepções de Matemática e de ensino de Matemática de professores na prática pedagógica. Zetetiké, v. 5, n. 8, p. 11-43, jul./dez. 1997.

THOMPSON, A. The relationship of teachers' conceptions of Mathematics teaching to instructional practice. Educational Studies in Mathematics. San Diego, n. 15, p. 105-127. 1984.

Submetido em Abril de 2014. Aprovado em Julho de 2014. 